\title{
A Study of Assessment Centre Practices of Multinational Enterprises operating in India-An Empirical Study of Private Sector Companies
}

\author{
Dr. Andrew Dutta, (Dean Academic) \\ Xavier University Bhubaneswar
}

\begin{abstract}
Assessment of competencies is relatively a new practice in the field of human resource management in India. Historically it is not the first choice of talent assessment due to high costs of design and deployment of Assessment Centres (henceforth AC) (Thornton, Rupp and Hoffman, 2015) and due to business education curriculum still lacking Assessment Center (AC) practices as course offerings. While systematic studies are reported from developed countries Spychalski, et al., (1997), Thornton III \& Rupp (2006), Hirose (2016) and from developing countries (Krause et.al, 2011), there are almost no studies reported from India on the spectrum of AC characteristics and practices. This study is an attempt to fill that gap. The study was conducted across $\mathrm{N}=213$ multinational enterprises (MNEs) operating in private sector (non-federal), chosen based on market capitalization across fifteen industrial sectors, to understand the AC practice spectrum based on the International Taskforce on Assessment Center Guidelines (2015), USA. Commissioned as a self-funded research, the insights from the study reveal that $46 \%$ of the MNEs do not conduct any systematic talent assessment in India through AC processes. The reasons range from lack of trained in-house assessors to "lack of faith" in the process of an AC. Of the remaining 54\% MNEs reporting AC practices, heterogeneity was found across various AC parameters such as job design, assessee groups, quality of assessors, assessment tools, AC characteristics, integration of data, assessee feedback processes and diagnostic methods to name a few. The finding of this study would help practitioners and decision makers to adopt suitable talent assessment strategies while operating businesses in India. It also builds a foundation to revisit extant theoretical literature on assessment centre from the developing country perspective.
\end{abstract}

Keywords: Assessment Center, human resource management, talent assessment, multinational enterprises in India, competency assessment. 


\section{$2^{\text {nd }}$ International Conference on Advanced Research in Social Sciences \& Humanities}

\section{Introduction}

In spite of the global recession since 2008, India is a robust market economy and a preferred investment and operational destinations for global multinational enterprises (MNEs) (Khare, 2017). Although supply of workforce is abundant at lower costs, concerns about the quality and competencies of the workforce has remained a concern and challenge for MNE managers in India (Prikshat et.al., 2018). An assessment centre is a comprehensive, standardized procedure in which multiple assessment techniques such as situational exercises and job simulations (business games, discussions, reports, and presentations) are used to evaluate multiple participants simultaneously by multiple assessors for a variety of manpower decisions (Rao \& Juneja, 2007, International Taskforce on Assessment Center Guidelines, 2015). Some of the reasons for which an assessment centre may be used are selection, promotion, placement, training and development. A wide variety of evidence has accumulated demonstrating the validity of Assessment Centers for selection (Thornton III \& Rupp, 2006). Studies have also successfully shown the validity of predicting job success using the Assessment Center approach (Holling \& Reiners, 1994). Because of the quality research and high incidence of reported validity, the methodology finds widespread use in many organizations (Rao \& Juneja, 2007). Recently, Herd, Alagaraja, \& Cumberland, (2015) used ACs for leadership development of global managers in the overall talent management framework in MNE context.

The AC process allows assessors to observe behavior and directly measure performance objectively against the specific key criteria or competencies that they consider important for a role. It gives an objective basis of what the individual can do and not what he says he can do. Assessment Centers are costly and time consuming to run. Employers invest a great deal in ensuring that the process is relevant to the requirements of their organization yet also gives the employees a fair opportunity to demonstrate their skills and personal qualities.

The Guidelines and Ethical Considerations for Assessment Center Operations (Rupp et al., 2015) are a statement of the considerations believed to be most important for all users of the Assessment Center method. These guidelines, which first came out in 1975 the USA, have gone through multiple revisions over the years with the latest revision appearing in 2014. They are the bed rock of all the Assessment Center activities carried out across all organizations in the world.

\section{Theoretical Foundations}

The Assessment Center methodology has been in vogue for quite some time now. AT\&T and IBM in the United States was its first proponent in the industrial domain and started using it from the late 1950's although similar methods were used by the military much before that. The application of Assessment Center methodology in the Indian context is also quite old with L\&T being the first company which started with the experimentation in the country. Although many companies in the mid-1970s, like Crompton Greaves, Ballarpur Industries, tried to adopt the framework they failed due to high cost of AC per participant, lack of trained assessors and employee antagonism. It was after the deregulation of the Indian economy in 1991 that the popularity of Assessment Centers 


\section{$2^{\text {nd }}$ International Conference on Advanced Research in Social Sciences \& Humanities}

Munich, Germany

really took off in India. Today many companies in India use it for measuring managerial talent and measuring it periodically. Shermon, (2004) lists a number of Indian organizations having very welldefined Assessment Centers.

While Assessment Centers have been used in India for the past several decades with significant changes taking place especially the last fifteen to twenty years (Prikshat et.al., 2018), no study has been reported in the academic literature identifying the practices followed by private sector organizations in India. This study will be the first of its kind in India and help gain scholars and managerial practitioners of AC an insight into the current practices followed in India and benchmark them with similar studies from developing countries that followed the characteristics prescribed by the Guidelines and Ethical Considerations for Assessment Center Operations 2014 in their ACs in organizations.

\section{Objective of this Study}

The objective of this study is to use the framework prescribed by past literature with a view of addressing their limitations in the context of organizations in India. Rao \& Juneja, (2007) pointed out that Indian organizations currently suffer from many inadequacies with regards to their Assessment center methodology. Some of these organizations lack proper behavioural description of competencies, trained assessors are not available; assessors who are available are not adequately trained in international best practices and guidelines; inter-rater reliability issues; appropriateness of dimensions measured, reliability of selection tools and exercises; organizational commitment ; involvement of line managers; feedback to participants and data security to name a few. Also, many organizations do not check the reliability and validity of the methods used after the AC processes.

This study reports large spectrum of assessment center practices pertaining to all the stages of the Assessment center process. The recommended characteristics as prescribed in the Guidelines and Ethical Considerations for Assessment Center Operations 2014 such as job analysis, classification of candidates, design, assessor training, evaluation and reliability (Krause \& Gebert, 2003) were followed for this study. Comparisons of the practices from the MNEs operating in India with those of other countries based on past studies were undertaken. Such comparative methods have been successfully employed by Krause \& Gebert, (2003); Krause et.al., (2011); Kudisch et al., (2001); Spychalski et.al.,(1997) and Hirose, (2016). The study then analyzes the differences of the practices of these organizations vis-à-vis those prescribed in Guidelines and Ethical Considerations for Assessment Center Operations (Rupp et al., 2015) with similar practices reported from South African context (Krause et.al., 2011). 


\section{$2^{\text {nd }}$ International Conference on Advanced Research in Social Sciences \& Humanities}

Munich, Germany

\section{Data and Methods}

Data was collected using an online survey completed by senior managers of human resource function. The questionnaire was designed from prior studies reporting AC practices from various countries. A total of 41 AC characteristics, divided in further sub-characteristics were chosen for the survey with 37 closed ended question and 4 open ended questions. Top 500 private sector companies operating in India were chosen based on total market capitalization for the financial year 2017-18 as the sample size. Companies having overseas sales or operations were $\mathrm{N}=411$ based on recently developed typology by Monaghan and Tippmann (2018). An online survey was sent to the office of human resources of these companies asking them to respond to the survey. Respondents were allowed to make multiple selections of responses which they found to be practiced in their companies. Completely filled and usable responses were found to be $\mathrm{N}=213$ making a response rate of 42.6 percent. This study envisaged that ensuring a large sample size will not only ensure maximum possible coverage in terms of the number of organizations $(\mathrm{N})$ but also in terms of industries and sectors. A total of fifteen industry sectors were covered by 411 organizations. The survey questionnaire was based on both multiple choice and open ended questions, developed from similar studies carried out in other countries (Krause \& Gebert, 2003; Krause \& Thornton III, 2009; Kudisch et al., 2001; Spychalski et al., 1997 and Hirose, 2016). In order to encourage maximum participation, the questionnaire was administered with assurance of anonymity and declaration of confidentiality of company responses. Although some studies reported very elaborate test of differences for many AC characteristics, comparing with developed nations, (Eurich et.al., 2009), the low response rate of the present study and lack of prior research in this field allowed this study to selectively go for statistical testing of differences on some parameters when compared with similar studies from the developing nations (Krause et.al., 2011).

\section{Results}

Only $\mathrm{n}=115$ private sector MNEs out of $\mathrm{N}=411$ organizations reported $\mathrm{AC}$ activities and assessment center methodologies. This was only $54 \%$ of the responding companies. However, of the total MNEs, this represented only $27.98 \%$ of $\mathrm{N}=411$ companies, which is significantly smaller compared to other countries where such studies have been reported (Eurich et.al., 2009; Spychalski et.al., 1997; Krause \& Gebert, 2003; Krause et.al., 2011 and Hirose, 2016). The cause for not having an AC process attributed by $n=98$ MNEs were high design and deployment cost, lack of trained assessors and lack of awareness of senior human resource managers about proper methods of assessment center. Although high costs of AC have been earlier reported to be a deterrent Thornton et.al. 2015) validity studies of AC also reported the long term benefits of AC outweighing the costs (Bhagat and Prien, 1996). The results reported here are for the 115 organizations that reported presence of AC methods in their companies. The cause that contributed maximum for the presence of AC in these companies were 'promotion for internal upward mobility' (76\%), followed by 'reasons for personnel 


\section{$2^{\text {nd }}$ International Conference on Advanced Research in Social Sciences \& Humanities}

\section{6 - 8 December ,2019}

Munich, Germany

development' (64\%)[see footnote]. $82.6 \%$ of the companies reported conducting a thorough analysis of job prior to conducting of an AC using structured job analysis methods such as Position Analysis Questionnaire or critical incident techniques. It was an interesting revelation that $89 \%$ of the companies $(n=102)$ used AC with the help of external consulting organizations as a turnkey project. This finding is in line with causes attributed by those organizations which do not conduct AC due to lack of trained in-house assessors and lack of proper know-how. 61.4\% $(\mathrm{n}=70)$ of the companies reported using more than six competencies during an AC. Using more dimensions have been reported in previous studies of AC validity to lower the

effectiveness (Bowler \& Woehr, 2006). This has serious ramifications for MNEs operating in India as the assessment of managers may not reflect the true future performance capabilities, given the fact that the single largest cause for deploying an AC is mainly for promotion and filling the leadership pipelines. Less than four competencies were reported by only $10.52 \%(\mathrm{n}=12)$ of companies and more than eight competencies were reported by only $8.77 \%(n=10)$, and the rest were in diverse ranges of competency assessments. Out of twenty five competency dimensions provide in the survey questionnaire, the competency dimensions that were most frequently used ${ }^{1}$ in ACs were 'achievement orientation' $(71.92 \%, \mathrm{n}=82)$, 'creative and innovative thinking' $(69.29 \% \mathrm{n}=79)$, 'execution skills' $(64.03 \% \mathrm{n}=73)$, 'team management' $(50.87 \% \mathrm{n}=58)$ and 'resource management $(36.84 \% \mathrm{n}=42)$. Surprisingly, 'service orientation' as a competency dimension for assessment scored as the least used dimension in AC practices in India with only 10 companies (8.77\%) reporting this dimension. The duration of the AC process reported by companies show that it lasts for two days for $56.5 \%(\mathrm{n}=65)$ companies with only $7.82 \%(\mathrm{n}=9)$ companies reporting more than four days of AC process in their companies. Compared with previous studies by Spychalski et al. (1997) (2-3 days), Krause and Gebert (2003) (up to 3 days), and Krause and Thornton (2009) (1-2 days), the finding reflects that ACs in India are as leaner as in other countries.

Table 1 shows the differences on various characteristics of AC when compared with similar findings from South Africa. Such comparative studies would serve as benchmarking (Krause et.al., 2011) of $\mathrm{AC}$ practices from economic and business contexts similar to India and would lead to better learning of AC practices from those countries which have already progressed ahead in this count on international benchmarks and globally accepted guidelines. Significant differences were observed on linkage between job requirements and exercises in competency tool matrix, pretesting of AC exercises, assessor qualities post assessor training, completion of reports by assessors, possibility of re-assessment for assesses and validation studies for an AC. This indicates that although there are close overlap of practices from similar developing countries with respect to AC practices, Indian assessment center activities are not fully following commonly accepted international guidelines on AC methods. No differences were observed on basic characteristics of design and deployment of ACs such as conducting detailed job analysis, using rotation plans for assessors and assesses, maintain job-competency modelling and basic performance management framework for offsetting AC results. There is, therefore, scope for future systematic studies designed to find out the various causes of such deviation from internationally accepted practices. This study shows the heterogeneity of AC practices

As respondents were allowed to select multiple responses on an item, the summation of the percentages would be more than hundred. 


\section{$2^{\text {nd }}$ International Conference on Advanced Research in Social Sciences \& Humanities}

\section{6 - 8 December ,2019}

Munich, Germany

in the Indian private sector MNEs and finds that AC practices are yet to mature in one of the fastdeveloping economies of the world and is yet to catch-up on globally accepted norms and standards of design, development and deployment of assessment centres.

Table 1

AC Characteristics when compared with Krause et.al. (2011)

AC Characteristics ${ }^{a}$

Job Analysis conducted prior to AC

Linkage between job requirements and exercises documented in a competency

by exercise matrix

Pretesting of exercises

Rotation plan used for Assessors and

Assessee

Evaluation of the qualities of

observational and rating skills of each

assessor after the assessor training

Job requirements/dimensions assessed

Assessors complete report before

integration process

Tool Result offsets

Dimension Result offsets

Reassessment Possibility

Validity Evaluation of AC

$\begin{array}{cc}\text { Present } & \text { Krause at.al } \\ \text { Study }^{\mathrm{c}} \% & \% \\ (\mathrm{~N}=115) & (\mathrm{N}=43) \\ 82.6 & 84 \\ 66.95 & 93\end{array}$

71.3

61.74

89.56

57.39

91.30

46

75

91.3

60

21.73

32.17
Chi-Square Test

Value, ( $\mathrm{p}$ values at $0.05)^{b}$

$0.0273(0.868703)^{*}$

11.0669 (0.000879)

$5.6439(0.017516)$

$2.9714(0.084747)^{*}$

$5.7729(0.016275)$

$1.4936(0.221664)^{*}$

$7.7433(0.005391)$

$0.9507(0.329549)^{*}$

$0.5456(0.460123)^{*}$

$19.1709(0.000012)$

$20.3439(0.00001)$

a: Percentages refer to percentage of organizations reporting the characteristics of AC b: *NS: non-significant

c Percentages are not rounded 


\title{
$2^{\text {nd }}$ International Conference on Advanced Research in Social Sciences \& Humanities
}

\author{
6 - 8 December ,2019 \\ Munich, Germany
}

\section{References}

1. Bhagat, R., and K. Prien. 1996. "Cross-Cultural Training in Organizational Contexts.” In Handbook of Intercultural Training, edited by D. Landis, J. Bennett, and M. Bennett, 216-230. Thousand Oaks, CA: Sage.

2. Bowler, M. C., \& Woehr, D. J. (2006). A meta-analytic evaluation of the impact of dimension and exercise factors on assessment center ratings. Journal of Applied Psychology, 91(5), 1114.

3. Eurich, T. L., Krause, D. E., Cigularov, K., \& Thornton, G. C. (2009). Assessment centers: Current practices in the United States. Journal of Business and Psychology, 24(4), 387.

4. Herd, A.M., Alagaraja, M., \& Cumberland, D.M. (2015) Assessing global leadership competencies: the critical role of assessment centre methodology. Human Resource Development International, 1-17.

5. Hirose, S. (2016). Assessment Center Practices in Japan: A Brief History and Challenges. In Assessment Centres and Global Talent Management (pp. 471-482). Routledge.

6. Holling, H., \& Reiners, W. (1994) Utility Analysis of Assessment Centers using objective profit data. Web published document.

7. Khare, A. K. (2017). Foreign Direct Investment-A Roadmap for Indian Economic Growth. International Journal of Engineering Technology Science and Research, 4(6), 752-765.

8. Krause, D.E., \& Gebert, D. (2003) A Comparison of Assessment Center Practices in Organizations in Germanspeaking Regions and the United States. International Journal of Selection and Assessment, 11(4), 297-312.

9. Krause, D.E., Rossberger, R.J., Dowdeswell, K., Venter, N., \& Joubert, T. (2011) Assessment center practices in South Africa. International Journal of Selection and Assessment, 19(3), 262-275.

10. Krause, D.E., \& Thornton III, G.C. (2009) A cross-cultural look at assessment center practices: survey results from Western Europe and North America. Applied Psychology, 58(4), 557-585.

11. Kudisch, J., Avis, J., Fallon, J., Thibodeaux, H., Roberts, F., Rollier, T., et al. (2001) A survey of assessment center practices in organizations worldwide: Maximizing innovation or business as usual 16th annual conference of the Society for Industrial and Organizational Psychology, San Diego, CA.

12. Monaghan, S., \& Tippmann, E. (2018). Becoming a multinational enterprise: Using industry recipes to achieve rapid multinationalization. Journal of International Business Studies, 49(4), 473-495.

13. Prikshat, V., Kumar, S., Nankervis, A., \& Khan, M. M. S. (2018). Indian HR competency modelling: Profiling, mapping and an investigation of HRM roles and competencies. The Journal of Developing Areas, 52(4), 269282.

14. Rao, T., \& Juneja, M. (2007) Is Past Performance a Good Predictor of Future Potential?: Indian Institute of Management Ahmedabad, Research and Publication Department.

15. Rupp, D.E., Hoffman, B.J., Bischof, D., Byham, W., Collins, L., Gibbons, A., et al. (2015) Guidelines and Ethical Considerations for Assessment Center Operations. Journal of Management, 0149206314567780.

16. Shermon, G. (2004). Competency based HRM: A strategic resource for competency mapping, assessment and development centres: Tata McGraw-Hill Education.

17. Spychalski, A.C., Quiñones, M.A., Gaugler, B.B., \& Pohley, K. (1997) A survey of assessment center practices in organizations in the United States. Personnel Psychology, 50(1), 71-90.

18. Thornton III, G.C., \& Rupp, D.E. (2006). Assessment centers in human resource management: Strategies for prediction, diagnosis, and development: Psychology Press.

19. Thornton, G. C., D. E. Rupp, and B. Hoffman. 2015. Assessment Center Perspectives for Talent Management Strategies. New York: Routlege

20. International Taskforce on Assessment Center Guidelines. (2015). Guidelines and ethical considerations for assessment center operations. Journal of Management, 41(4), 1244-1273. 